\title{
Cobalt(II)-Selective Membrane Electrode Based on a Recently Synthesized Benzo-Substituted Macrocyclic Diamide
}

\author{
Mojtaba ShamsiPur,* Tahereh Poursaberi,** Shohre Rouhani,** Khodabakhsh Niknam,*** \\ Hashem SHARGHI, $* * *$ and Mohammad Reza GanJaLI**†
}

*Department of Chemistry, Razi University, Kermanshah, Iran

**Department of Chemistry, Tehran University, Tehran, Iran

***Department of Chemistry, Shiraz University, Shiraz, Iran

\begin{abstract}
A PVC-membrane electrode based on a recently synthesized 18-membered macrocyclic diamide is presented. The electrode reveals a Nernstian potentiometric response for $\mathrm{Co}^{2+}$ over a wide concentration range $\left(2.0 \times 10^{-6}-1.0 \times 10^{-2} \mathrm{M}\right)$. The electrode has a response time of about $10 \mathrm{~s}$ and can be used for at least 2 months without any divergence. The proposed sensor revealed very good selectivities for $\mathrm{Co}^{2+}$ over a wide variety of other metal ions, and could be used over a wide $\mathrm{pH}$ range $(3.0-8.0)$. The detection limit of the sensor is $6.0 \times 10^{-7} \mathrm{M}$. It was successfully applied to the direct determination and potentiometric titration of cobalt ion.
\end{abstract}

(Received December 25, 2000; Accepted June 28, 2001)

Despite urgent need for a cobalt-responsive sensor for the potentiometric monitoring of $\mathrm{Co}^{2+}$ in many industrial, clinical, pharmaceutical, plant, soil and food samples, ${ }^{1}$ there have been only a few reports on cobalt ion-selective electrodes in the literature. ${ }^{2-7}$ However, most of these potentiometric sensors have not been very fruitful, because the developed electrodes possess a narrow working concentration range with a near Nernstian response and relatively long response times, and suffer serious interferences from various ions, including iron, nickel, sodium, zinc, copper and cadmium..$^{2-7}$ In recent years, we have used some aza and thia-substituted crown ethers as neutral carriers in membrane transport and in PVC membrane electrode studies of some transition and heavy-metal ions. ${ }^{8-11}$ In this paper, we report on the use of a new benzo-substituted macrocyclic diamide which was recently synthesized in our laboratories ${ }^{12}$ as an excellent neutral carrier in the construction of a cobalt(II)-PVC membrane electrode.

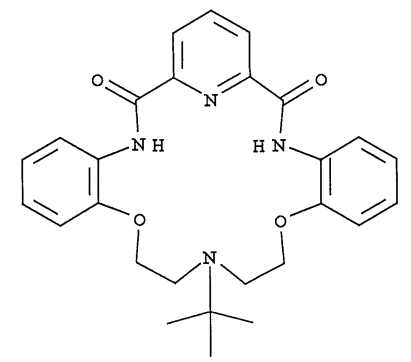

(L)

\section{Experimental}

\section{Reagents}

Reagent-grade benzyl acetate (BA), dibutyl phthalate (DBP), high relative-molecular weight $\mathrm{PVC}$, oleic acid (OA), sodium

\footnotetext{
$\doteqdot$ To whom correspondence should be addressed.

E-mail: Ganjali@khayam.ut.ac.ir
}

tetraphenylborate (STB) and tetrahydrofurane (THF) were purchased from Merck Chemical company and used as received. 9-t-Butyl-3,9,15,21-tetraaza-4,5,13,14-dibenzo-6,12dioxabicyclo[15.3.1]henicosa-1(21),17,19-triene-2,16-dione (L) was synthesized and purified as described elsewhere. ${ }^{12}$ Reagent-grade nitrate salts of the cations used (all from Merck) were of the highest purity available and used without any further purification, except for vacuum drying over $\mathrm{P}_{2} \mathrm{O}_{5}$. All other reagents were obtained from Fluka or Merck Chemical Companies and used as received. Triply distilled deionized water was used throughout.

\section{Synthesis of ionophore}

The ionophore 9-t-butyl-3,9,15,21-tetraaza-4,5,13,14-dibenzo6,12-dioxabicyclo[15.3.1] henicosa-1(21),17,19-triene-2,16dione (4) was synthesized in four steps (Scheme 1).

$N$-t-Butyl-di(2-chloroethyl)amine (1). $\quad N$-t-Butyl-di(2-hydroxyethyl)amine $(16 \mathrm{~g}, 0.1 \mathrm{~mol})$ in benzene $\left(120 \mathrm{~cm}^{3}\right)$ was cooled down to $5^{\circ} \mathrm{C}$ and thionyl chloride $\left(30 \mathrm{~cm}^{3}\right)$ was then added dropwise under efficient stirring. The reaction mixture was refluxed over $4 \mathrm{~h}$ and then brought down to room temperature and left to stand overnight. After cooling down again to $5^{\circ} \mathrm{C}$, a solution of sodium carbonate $(10 \%)$ was added until the $\mathrm{pH}$ was basic. The organic layer was then separated, dried over magnesium sulfate, filtered and evaporated to yield a colorless viscose liquid of $N$ - $t$ butyl-di(2-chloroethyl)amine $18 \mathrm{~g}, 63 \%$ yield.

$N$ - - -Butyl-bis(2-(o-nitrophenoxy)ethyl)amine (2). o-Nitrophenol $(0.1 \mathrm{~mol})$ and potassium carbonate $(14 \mathrm{~g})$ were mixed and stirred in DMF $\left(100 \mathrm{~cm}^{3}\right)$ for $3 \mathrm{~h}$. Then, the dichloride (1) $(0.05$ mol) was added dropwise during $4 \mathrm{~h}$ and the mixture was refluxed for three days. After cooling, the mixture was poured into ice, and the precipitate was filtered off. The precipitate was washed with distilled water, and the crude product was purified by column chromatography, using petroleum ether (bp $=60$ $\left.80^{\circ} \mathrm{C}\right) /$ ethyl acetate as eluent, to give the dinitro compound (2) as a white cream solid; yield $72 \%, \mathrm{mp}=172-173^{\circ} \mathrm{C}$. $N$-t-Butyl-bis(2-(o-aminophenoxy)ethyl)amine (3). The dinitro 

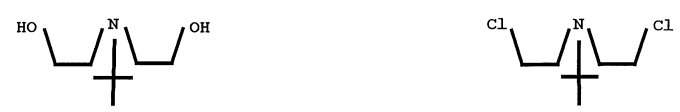

$$
\underset{\text { Benzene }}{\stackrel{\mathrm{SOCl}_{2}}{\longrightarrow}}
$$

D-Nitrophenol

$\mathrm{K}_{2} \mathrm{CO}_{3}$<smiles>CC1(C)CCC(COc2ccccc2[N+](=O)[O-])C(C)(C)CN1</smiles>

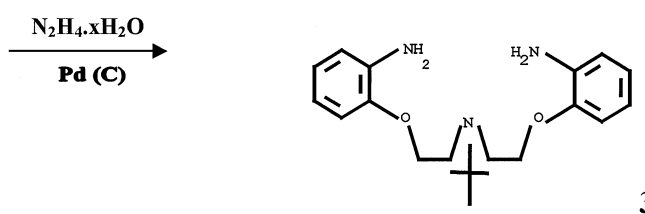

3
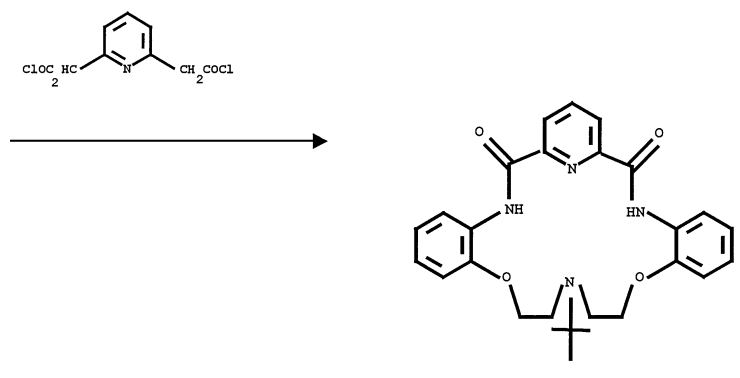

Scheme 1 Synthetic route.

compound (2) (4.0 g, $0.01 \mathrm{mmol})$ was reduced in a stirred refluxing solution tin(II) chloride dihydrate $(15 \mathrm{~g}, 0.65 \mathrm{~mol})$ in concentrated hydrochloric acid $\left(50 \mathrm{~cm}^{3}\right)$. After $7 \mathrm{~h}$, the reaction mixture was cooled and the precipitate was filtered off. A solution of sodium hydroxide $\left(5 \mathrm{M}, 200 \mathrm{~cm}^{3}\right)$ was added to the filtrate and extracted with $\mathrm{CH}_{2} \mathrm{Cl}_{2}\left(3 \times 250 \mathrm{~cm}^{3}\right)$. The organic layer was washed with water $\left(2 \times 200 \mathrm{~cm}^{3}\right)$, dried with sodium sulfate and evaporated. The residue was crystallized from ethanol to give diamine (3) as a white cream crystal in 54\% yield $(6 \mathrm{~g}): \mathrm{mp}=50-52^{\circ} \mathrm{C}$.

9-t-Butyl-3,9,15,21-tetraaza-4,5,13,14-dibenzo-6,12-dioxabicyclo[15.3.1] henicosa-1(21),17,19-triene-2,16-dione (4). A solution of diamine (3) $(2 \mathrm{mmol})$ in dry $\mathrm{CH}_{2} \mathrm{Cl}_{2}(50$ $\mathrm{cm}^{3}$ ) was added quickly to a vigorously stirring solution of 2,6pyridinedicarboxylic acid dichloride $(2 \mathrm{mmol})$ in dry $\mathrm{CH}_{2} \mathrm{Cl}_{2}$ $\left(50 \mathrm{~cm}^{3}\right)$ at room temperature. The reaction mixture was stirred for further $20 \mathrm{~min}$, and was then washed with bicarbonate solution $\left(2 \times 50 \mathrm{~cm}^{3}\right)$ and water $\left(2 \times 50 \mathrm{~cm}^{3}\right)$. The organic layer was dried over magnesium sulfate and the solvent was evaporated to give white cream crystals; yield 73\%; $\mathrm{mp}=177$ $179^{\circ} \mathrm{C}$; IR $\left(\mathrm{KBr}, \mathrm{cm}^{-1}\right)$ : $749.2(\mathrm{~m}), 1252.9(\mathrm{~m}), 1454.4(\mathrm{~m})$, 1528.6 (s), 1600 (m), 1682.8 (s), 2911.9 (w), 3382 (s); ${ }^{1} \mathrm{H}$ NMR $\left(\mathrm{CDCl}_{3}, 250 \mathrm{MHz}\right) ; \delta(\mathrm{ppm}) 0.95(\mathrm{~s}, 9 \mathrm{H}), 2.95(\mathrm{t}, 4 \mathrm{H}, J=5.65$ $\mathrm{Hz}), 4.23(\mathrm{t}, 4 \mathrm{H}, J=5.65 \mathrm{~Hz}), 7.01\left(\mathrm{dd}, 2 \mathrm{H}, J_{1}=7.50 \mathrm{~Hz}, J_{2}=\right.$ $2.00 \mathrm{~Hz}), 7.04-7.15(\mathrm{~m}, 4 \mathrm{H})(\mathrm{t}, 1 \mathrm{H}, J=7.80 \mathrm{~Hz}), 4.09(\mathrm{t}, 4 \mathrm{H}$, $6.05 \mathrm{~Hz}), 6.96-7.11(\mathrm{~m}, 4 \mathrm{H}), 7.46\left(\mathrm{dt}, 2 \mathrm{H}, J_{1}=7.95 \mathrm{~Hz}, J_{2}=\right.$ $1.65 \mathrm{~Hz}), 8.45\left(\mathrm{dd}, 2 \mathrm{H}, J_{1}=7.45 \mathrm{~Hz}, J_{2}=2.10 \mathrm{~Hz}\right), 8.51(\mathrm{~d}, 2 \mathrm{H}$,
$J=7.77 \mathrm{~Hz}), 10.16(\mathrm{~s}, 2 \mathrm{H})$; Mass $m / z(\%): 476\left(\mathrm{M}^{+}+2,12.6\right)$, $475\left(\mathrm{M}^{+}+1,34.6\right), 474\left(\mathrm{M}^{+}, 22.0\right), 461$ (19.7), 460 (62.9), 459 (46.6), 419 (12.1), 418 (13.0), 389 (3.9), 349 (2.0), 228 (4.0), 214 (4.3), 210 (5.2), 195 (7.4), 187 (6.6), 171 (9.6), 149 (5.8), 134 (18.0), 120 (14.7), 106 (13.4), 100 (36.4), 93 (7.6), 84 (35.2), 77 (19.8), 56 (base peak); UV (chloroform); $\lambda$, nm $\left(\varepsilon_{\max }\right)$ : 247.9 (12023), 306.4 (13990). Anal., Calcd for $\mathrm{C}_{27} \mathrm{H}_{30} \mathrm{~N}_{4} \mathrm{O}_{4}$ : C, 68.34; H, 6.37; N, 11.81. Found: C, 68.17; H, 6.51; N, 11.57.

\section{Electrode preparation}

The general procedure used to prepare the PVC membrane was to thoroughly mix $35 \mathrm{mg}$ of powdered PVC, $50 \mathrm{mg}$ of plasticizer BA, $5 \mathrm{mg}$ of oleic acid and $2 \mathrm{mg}$ of sodium tetraphenylborate in $5 \mathrm{~cm}^{3}$ of THF. To this solution was added $8 \mathrm{mg}$ of $\mathbf{L}$ and the solution was mixed well. The solvent was slowly evaporated until an oily concentrated mixture was obtained. A Pyrex tube $(8-10 \mathrm{~mm} \text { o.d. })^{14-25}$ was dipped into the mixture for about $10 \mathrm{~s}$ so that a nontransparent membrane of about $0.3 \mathrm{~mm}$ thickness was formed. The tube was then pulled out from the mixture and kept at room temperature for about 1 $\mathrm{h}$. The tube was then filled with an internal filling solution (1.0 $\times 10^{-3} \mathrm{M} \mathrm{CoCl}_{2}$ ). The electrode was finally conditioned for $24 \mathrm{~h}$ by soaking in a $1.0 \times 10^{-2} \mathrm{M}$ solution of cobalt chloride. A silver/silver chloride coated wire was used as an internal reference electrode. The ratio of various ingredients, concentrations of equilibrating solution and time of contact were optimized to provide membranes that result in reproducible, noiseless and stable potentials.

\section{Electromotive force measurements}

All emf measurements were carried out with the following assembly:

$\mathrm{Ag}-\mathrm{AgCl} /$ internal solution $\left(1.0 \times 10^{-3} \mathrm{M} \quad \mathrm{CoCl}_{2}\right) / \mathrm{PVC}$ membrane/test solution $/ \mathrm{Hg}_{2} \mathrm{Cl}_{2}, \mathrm{KCl}$ (satd.)

A Corning ion analyzer $250 \mathrm{pH} / \mathrm{mV}$ meter was used for potential measurements at $25.0 \pm 0.1^{\circ} \mathrm{C}$. The emf observations were made relative to a double-junction saturated calomel electrode (SCE, Philips) with the outer chamber filled with an ammonium nitrate solution. The activities were calculated according to the Debye-Hückel procedure. ${ }^{13}$

\section{Results and Discussion}

The existence of four nitrogens and two oxygen atoms in the structure of ligand as well as its sufficiently high rigidity and lipophilicity was expected to increase both the selectivity and stability of its transition and heavy-metal ion complexes over alkali and alkaline earth cations., ${ }^{9,1}$ Thus, in order to check the stability of the macrocyclic diamide $\mathbf{L}$ as an ion carrier, in preliminary experiments, it was used to prepare PVC membrane ion-selective electrode for a wide variety of metal ions including alkali, alkaline earth, transition and heavy metal ions. The potential responses of various ion-selective electrodes based on $\mathbf{L}$ are shown in Fig. 1. As is quite obvious, except for the $\mathrm{Co}^{2+}$ ion-selective electrode, in all other cases the slope of the corresponding potential-pM plots is much lower than the excepted Nernstian slopes of 59 and $29.5 \mathrm{mV}$ per decade for univalent and bivalent cations, respectively. Figure 1 shows that the sensitivity of the resulting potential responses decrease in the order $\mathrm{Co}^{2+}>\mathrm{Ni}^{2+}>\mathrm{Cu}^{2+}>\mathrm{Hg}^{2+}>\mathrm{K}^{+}>\mathrm{Na}^{+}>\mathrm{Zn}^{2+}>\mathrm{Pb}^{2+}$ $>\mathrm{Cd}^{2+}>\mathrm{Ba}^{2+}>\mathrm{Sr}^{2+}>\mathrm{Ca}^{2+}>\mathrm{Fe}^{3+}>\mathrm{Mg}^{2+}$.

Since the sensitivity and selectivity obtained for a given ionophore depend significantly on the membrane ingredients, the nature of solvent mediators and additives used, ${ }^{17,26-28}$ the 

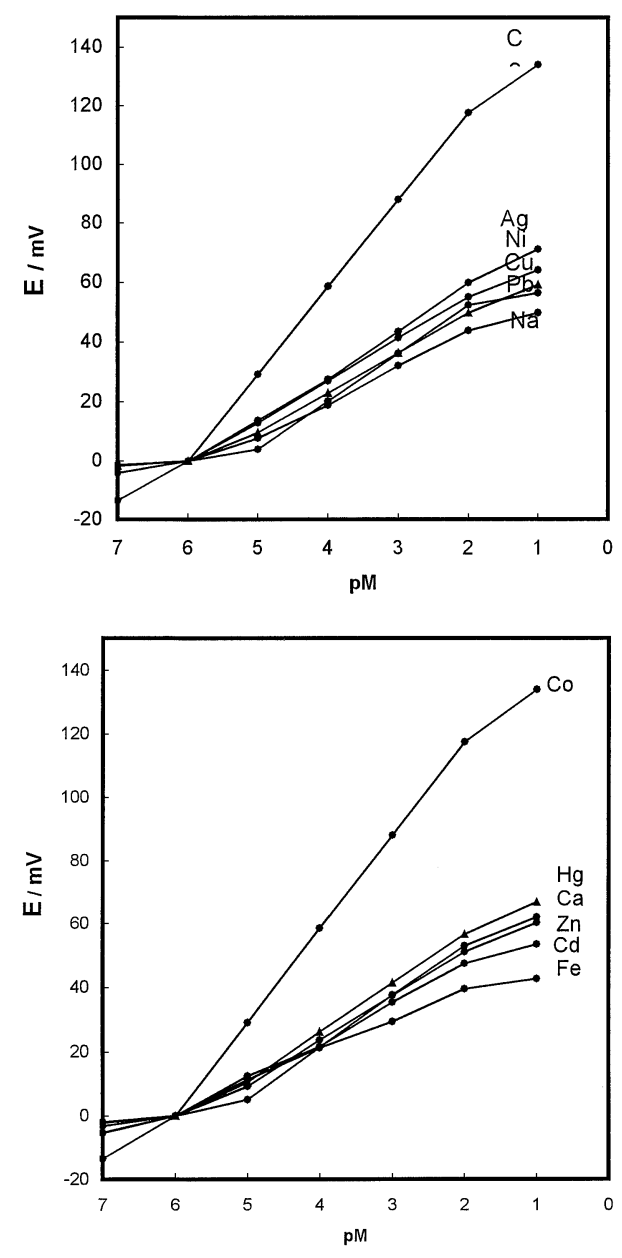

Table 1 Optimization of membrane ingredients

\begin{tabular}{ccccccc}
\hline & \multicolumn{6}{c}{ Composition, \% } \\
\cline { 2 - 7 } $\begin{array}{c}\text { Membrane } \\
\text { No. }\end{array}$ & PVC & Plasticizer & L & OA & STB & $\begin{array}{c}\text { Slope } \\
(\mathrm{mV} / \text { decade })^{\mathrm{a}}\end{array}$ \\
\hline 1 & 33 & 67, DBP & - & - & 0 & \\
2 & 33 & 66, DBP & 1 & - & - & 5.2 \\
3 & 33 & 64, DBP & 3 & - & - & 8.0 \\
4 & 33 & 62, DBP & 5 & - & - & 10.2 \\
5 & 33 & 60, DBP & 7 & - & - & 10.9 \\
6 & 33 & 58, DBP & 9 & - & - & 10.7 \\
7 & 33 & 59, DBP & 8 & - & - & 11.3 \\
8 & 33 & 59, BA & 8 & - & - & 14.2 \\
9 & 33 & 58, BA & 8 & - & 1 & 16.9 \\
10 & 33 & 57, BA & 8 & - & 2 & 21.5 \\
11 & 33 & 56, BA & 8 & - & 3 & 21.0 \\
12 & 30 & 55, BA & 8 & 5 & 2 & 29.0 \\
13 & 33 & 49, BA & 8 & 8 & 2 & 27.1 \\
14 & 33 & 54, BA & 8 & 5 & - & 22.5 \\
15 & 33 & 49, BA & 8 & 10 & - & 27.5 \\
16 & 33 & 44, BA & 8 & 15 & - & 28.3 \\
\hline
\end{tabular}

a. Standard deviations on the slopes are at the most $\pm 0.9 \mathrm{mV} / \mathrm{decade}$.

Fig. 1 Potential response of various ion-selective electrodes based on $(\mathbf{L})$.

effects of the membrane composition, nature and amount of plasticizer, amount of oleic acid and sodium tetraphenylborate as efficient lipophilic additives on the potential response of the $\mathrm{Co}^{2+}$ ion-selective electrode were investigated. The results are summarized in Table 1. As can be seen from Table 1, among the two different plasticizers used, benzyl acetate resulted in the best sensivity. Table 1 also shows that with the increasing the amount of ionophore, up to a value of $8 \%$, the sensitivity is increased, although the slope of emf $v s$. log concentration plot is at the most one-half of the expected Nernstian value. However, the additon of OA (Nos. 14-16) or STB (Nos. 9-11) will increase the sensitivity of the electrode response considerably. It is well known that the presence of lipophilic anions in cationselective membrane electrodes not only diminish the ohmic resistance ${ }^{29}$ and enhance the behavior and selectivity, ${ }^{30}$ but also in cases where the extraction capability is poor, increase the sensitivity of the membrane electrodes. ${ }^{31}$

It is interesting to note that the use of neither OA nor STB alone can induce a perfect Nernstian behavior of the electrode, although the use of $15 \%$ OA (No.16) seem to be superior to that of 2\% STB (No.10). However, the use of a mixture of both additives (i.e. 5\% OA and 2\% STB, No.12) will show a kind of synergestic effect in improving the emf response of the electrode to a nice Nernstian behavior. It should be noted that we have recently reported the first use of oleic acid as a very suitable lipophilic additive in inducing permselectivity to some PVC-based ion-selective electrodes..$^{8-11,14,18-20}$ As can be seen

from Table 1, the membrane with a PVC:BA:L:OA:STB percent ratio of 30:55:8:5:2 shows a Nernstian behavior over a wide concentration range.

The influence of the concentration of internal solution on the potential response of the $\mathrm{Co}^{2+}$ ion-selective electrode was studied. It was found that the variation in the concentration of the internal solution from $1.0 \times 10^{-2} \mathrm{M}$ to $1.0 \times 10^{-4} \mathrm{M}$ does not cause any significant difference in the potential response of the electrodes, except for an expected change in the intercept of the resulting Nernstian plots. A $1.0 \times 10^{-3} \mathrm{M}$ concentration of internal solution is quite appropriate for smooth functioning of the electrode system.

The optimum equilibration time for the sensor is $12 \mathrm{~h}$ when it is placed in a $1.0 \times 10^{-2} \mathrm{M} \mathrm{CoCl}_{2}$ solution. It then generates stable potentials when placed in contact with $\mathrm{Co}^{2+}$ solutions. The critical response characteristic of the electrode was assessed according to IUPAC recommendation. ${ }^{32}$ The emf response of the membrane at varying concentration of $\mathrm{Co}^{2+}$ ion (Fig. 1) indicates a rectilinear range from $1.0 \times 10^{-6}-1.0 \times 10^{-2} \mathrm{M}$. The slopes of the calibration curves were $29.45 \pm 0.5 \mathrm{mV}$ per decade of $\mathrm{Co}^{2+}$ concentration. The limit of detection, obtained from the intersection of the two extrapolated segments of the calibration graph, was $6.0 \times 10^{-7} \mathrm{M}(36 \mathrm{ppb})$.

The average time required for the $\mathrm{Co}^{2+}$ ion sensor to reach a potential within $\pm 1 \mathrm{mV}$ of the final equilibrium value after successive immersion of a series of cobalt(II) ion solutions, each having a 10-fold difference in concentration, was measured. The static response time of the membrane sensor thus obtained was $<10 \mathrm{~s}$ for concentrations $\geq 1.0 \times 10^{-3} \mathrm{M}$ (see Fig. 2) and $<15 \mathrm{~s}$ for concentrations of $\geq 10^{-6} \mathrm{M}$. It should be noted that the equilibrium potential remained constant for more than $6 \mathrm{~min}$, after which only a slow divergence within the resolution of the potentiometer $( \pm 1 \mathrm{mV})$ was reported. The membrane electrode prepared could be used for at least 2 months (while keeping dry) without any measurable divergence. It should also be noted that the reuse of the dried electrode required further conditioning. The standard deviation of 10 replicate measurements is $\pm 0.4 \mathrm{mV}$.

The influence of the $\mathrm{pH}$ of the test solution on the potential response of the sensor was tested in the $\mathrm{pH}$ range $2.0-11.0$ and 


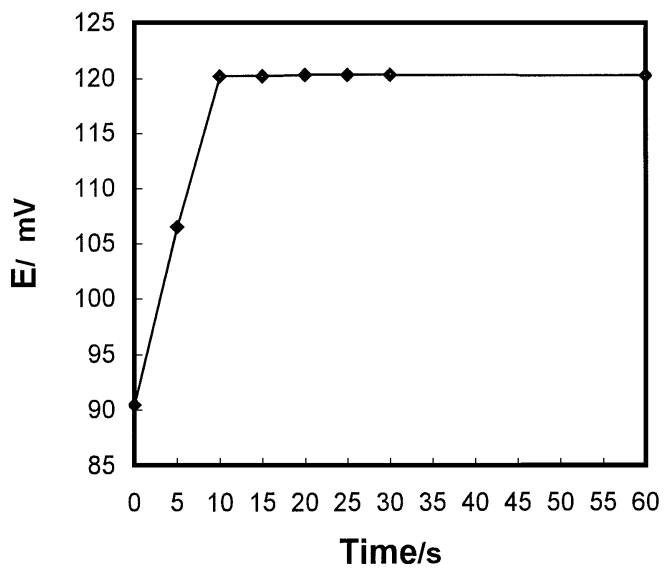

Fig. 2 Response time profile of the $\mathrm{Co}^{2+}$ ion-selective electrode.

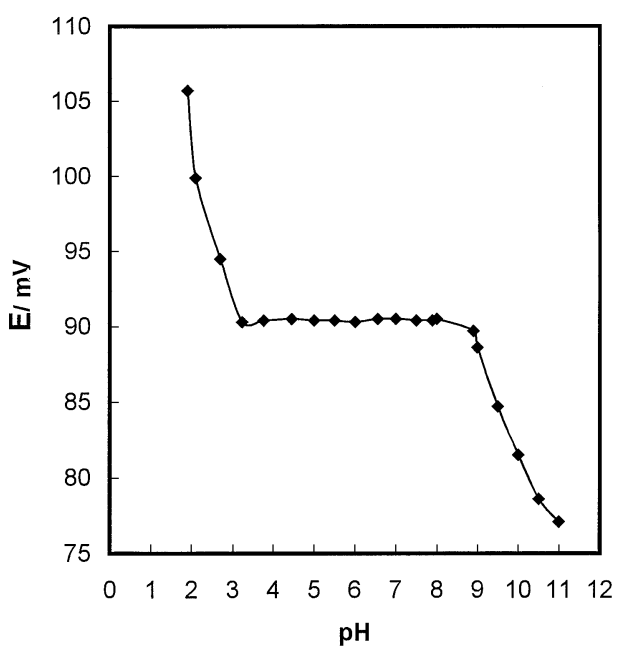

Fig. 3 Effect of the $\mathrm{pH}$ of the test solution $\left(1.0 \times 10^{-3} \mathrm{~mol} \mathrm{dm}^{-3}\right.$ $\left.\mathrm{Co}^{2+}\right)$ on the potential response of the $\mathrm{Co}^{2+}$ ion-selective electrode.

the results are shown in Fig. 3. As seen, the membrane electrode can be suitably used in the $\mathrm{pH}$ range 3.5-8.0. However, the observed changes below and above this $\mathrm{pH}$ range may be due to protonation of the $\mathbf{L}$ and formation of some hydroxy complexes of $\mathrm{Co}^{2+}$ ion in solution, respectively.

The potentiometric selectivity coefficients, which reflected the relative response of the membrane sensor for the primary ion over other ions, present insolution, is perhaps the most important characteristics of an ion-selective electrode. In this work, the potential responses of the proposed $\mathrm{Co}^{2+}$ ion-selective sensor to thirteen common cations were investigated by the matched potential method (MPM). ${ }^{33,34}$

This is recently a recommended method by IUPAC ${ }^{35}$ which gets rid of the limitations of the corresponding methods based on Nicolsky-Eisenmen equation for determining the potentiometric selectivity coefficient (including the fixed interference and the mixed solution methods). ${ }^{36}$ These limitations include non-Nernstian behavior of interfering ions and an inequality of the charges of the primary and interfering ions. According to the MPM, the selectivity coefficient is defined as the activity ratio of the primary ion (A) and the interfering ion (B) that gives the same potential change in a reference solution. ${ }^{33}$ Thus, first the change in potential upon changing the primary ion activity is measured, then the

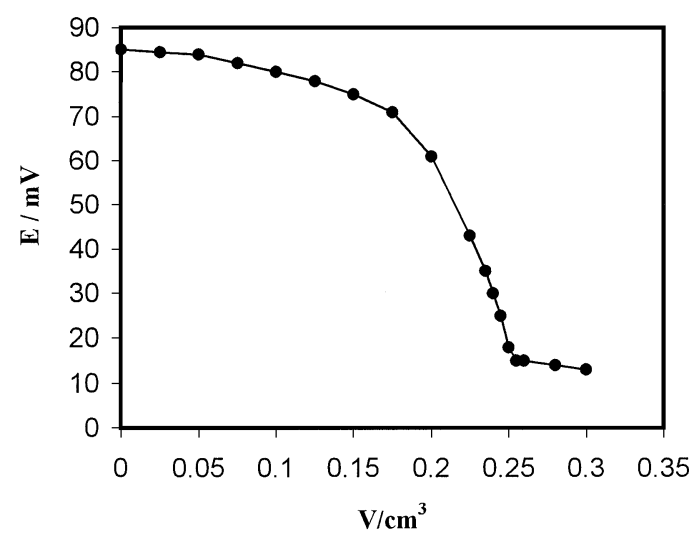

Fig. 4 Potentiometric titration curve of $45.0 \mathrm{~cm}^{3}$ of $1.0 \times 10^{-3} \mathrm{~mol}$ $\mathrm{dm}^{-3} \mathrm{Co}^{2+}$ solution with $2 \times 10^{-1} \mathrm{~mol} \mathrm{dm}-3$ of EDTA.

Table 2 Selectivity coefficient of various interfering ions $\left(\mathrm{M}^{n+}\right)^{\mathrm{a}}$

\begin{tabular}{llll}
\hline $\mathrm{M}^{n+}$ & \multicolumn{1}{c}{$K_{\mathrm{A}, \mathrm{B}}^{\text {pot }}$} & \multicolumn{1}{c}{$\mathrm{M}^{n+}$} & \multicolumn{1}{c}{$K_{\mathrm{A}, \mathrm{B}}^{\text {pot }}$} \\
\hline $\mathrm{Cu}^{2+}$ & $9.30 \times 10^{-3}$ & $\mathrm{Mg}^{2+}$ & $2.06 \times 10^{-4}$ \\
$\mathrm{Zn}^{2+}$ & $7.20 \times 10^{-3}$ & $\mathrm{~N}^{+}$ & $8.52 \times 10^{-3}$ \\
$\mathrm{Ni}^{2+}$ & $8.10 \times 10^{-2}$ & $\mathrm{~K}^{+}$ & $9.10 \times 10^{-3}$ \\
$\mathrm{Cd}^{2+}$ & $5.26 \times 10^{-3}$ & $\mathrm{Ca}^{2+}$ & $4.50 \times 10^{-3}$ \\
$\mathrm{~Pb}^{2+}$ & $7.10 \times 10^{-3}$ & $\mathrm{Sr}^{2+}$ & $4.94 \times 10^{-3}$ \\
$\mathrm{Hg}^{2+}$ & $8.50 \times 10^{-4}$ & $\mathrm{Ba}^{2+}$ & $5.1 \times 10^{-3}$ \\
$\mathrm{Fe}^{3+}$ & $2.70 \times 10^{-3}$ & & \\
\hline
\end{tabular}

a. Conditions: reference solution, $1.0 \times 10^{-5} \mathrm{M} \mathrm{CoCl}_{2}$; primary ion (A), $5.0 \times 10^{-5} \mathrm{M} \mathrm{Co}^{2+}$; interfering ions (B), $2.5 \times 10^{-1}-1.0 \times 10^{-4} \mathrm{M}, \mathrm{M}^{n+}$.

interfering ion would be added to an identical reference solution until the same potential change is obtained.

The selectivity coefficient $K_{\mathrm{A} . \mathrm{B}}^{\mathrm{pot}}$, is determined as

$$
K_{\mathrm{A} . \mathrm{B}}^{\mathrm{pot}}=\Delta A / a_{\mathrm{B}},
$$

where $\Delta A=a_{\mathrm{A}}^{\prime}-a_{\mathrm{A}}, a_{\mathrm{A}}$ is the initial primary ion activity and $a_{\mathrm{A}}^{\prime}$ the activity of $A$ in the presence of interfering ion, $a_{\mathrm{B}}$. It should be noted that the concentration of $\mathrm{Co}^{2+}$ used as primary ion in this study was $5.0 \times 10^{-5} \mathrm{M}$.

The resulting selectivity coefficient values thus obtained for the proposed $\mathrm{Co}^{2+}$ sensor are given in Table 2. As can be seen, for all cation used (except $\mathrm{Ni}^{2+}$ ), the selectivity coefficients are smaller than $10^{-2}$, which seem to indicate that the disturbance produced by these cations in the functioning of the $\mathrm{Co}^{2+}$ ionselective electrode is negligible. In Table 3, the response characteristics of the proposed membrane sensor are compared with those of the best $\mathrm{Co}^{2+}$-selective electrode reported before $^{2-5,7}$ From the data given in Table 3, it is immediately obvious that not only the response time and detection limit of the proposed electrode, but also its selectivity coefficients, are superior to those reported for other cobalt ion-selective electrodes, especially for interfering ions such as $\mathrm{Ni}^{2+}, \mathrm{Na}^{+}$, $\mathrm{Zn}^{2+}, \mathrm{Cd}^{2+}$ and $\mathrm{Fe}^{3+} \cdot{ }^{2-7}$

The proposed $\mathrm{Co}^{2+}$ membrane electrode was found to work well under laboratory conditions. It was applied to the titration of $\mathrm{a} \mathrm{Co}^{2+}$ ion solution with an EDTA solution; the resulting curve is shown in Fig. 4. As can be seen, the amount of $\mathrm{Co}^{2+}$ ion in solution can be accurately determined with the electrode. The electrode was also successfully applied to the direct 
Table 3 Comparison of serious interfering ions of different $\mathrm{Co}^{2+}$ ion-selective

\begin{tabular}{|c|c|c|c|c|}
\hline Carrier & Response time & Serious interfering ion & Detection limit & Ref. \\
\hline $\begin{array}{l}5,7,7,12,14,14-\text { Hexa } \\
\text { methyl-1,4,8,11-tetra } \\
\text { azacyclotetradeca-4,11- } \\
\text { diene diperchlorate }\end{array}$ & $20 \mathrm{~s}$ & $\mathrm{Na}^{+}, \mathrm{Ni}^{2+}, \mathrm{Fe}^{3+}$ & $8.0 \times 10^{-6} \mathrm{M}$ & (7) \\
\hline $\begin{array}{l}\text { Cobalt phenanthroline } \\
\text { complexes }\end{array}$ & $20 \mathrm{~s}$ & $\mathrm{Cu}^{2+}, \mathrm{Zn}^{2+}, \mathrm{Fe}^{2+}, \mathrm{Cd}^{2+}$ & $1.0 \times 10^{-6} \mathrm{M}$ & (4) \\
\hline Grafted copolymer & - & $\mathrm{K}^{+}, \mathrm{Ca}^{2+}, \mathrm{Cu}^{2+}, \mathrm{Ni}^{2+}$ & $2.0 \times 10^{-7} \mathrm{M}$ & (5) \\
\hline $\begin{array}{l}\text { Tributyl octadecyl } \\
\text { ammonium tetrathio- } \\
\text { cyanatacobaltate(II) }\end{array}$ & $40 \mathrm{~s}$ & $\mathrm{Fe}^{3+}, \mathrm{Sn}^{2+}, \mathrm{Zn}^{2+}$ & $1.0 \times 10^{-5} \mathrm{M}$ & (2) \\
\hline$(\mathbf{L})$ & $10 \mathrm{~s}$ & $\mathrm{Ni}^{2+}$ & $6.0 \times 10^{-7} \mathrm{M}$ & This work \\
\hline
\end{tabular}

determination of cobalt in wastewater samples from the cobalt acid baths taken from Tehran electroplating factory. The cobalt content obtained from five replicate measurements $(0.43 \pm 0.02$ ppm) was found to be in satisfactory agreement with that determined by atomic absorption spectrometry $(0.42 \pm 0.01$ ppm).

\section{Conclusion}

This work demonstrates that 9-t-butyl-3,9,15,21-tetraaza4,5,13,14-dibenzo-6,12-dioxabicyclo[15.3.1]henicosa1(21),17,19-triene-2,16-dione ( $\mathbf{L})$ can be used as a new ionophore in the development of a PVC-based cobalt ionselective electrode. The electrode responds to $\mathrm{Co}^{2+}$ in a Nerstian fashion and displays good selectivity and detection limit. The electrode characterized by a relatively fast response, reasonable long-term stability and responsive potential stability. The proposed $\mathrm{Co}^{2+}$-membrane electrode was applied to the direct determination of cobalt ions in wastewater of an electroplating bath as well as the titration of $\mathrm{Co}^{2+}$ solution with EDTA.

\section{Acknowledgements}

The authors express their appreciation to the University of Tehran Research Council for financial support of this work.

\section{References}

1. S. P. Parker, "McGraw Hill Consise Encyclopedia of Science and Technology", 1984, McGraw-Hill, New York, 390.

2. A. A. Obmetko, E. M. Pakhman'ko, and V. L. Lomako, Zh. Anal. Khim., 1990, 45, 1592.

3. A. M. Volovik, V. N. Tolmachev, and L. V. Miroshnik, Zh. Anal. Khim., 1985, 40, 481.

4. S. S. M. Hassan and W. H. Mahmoud, Mikrochim. Acta, 1995, 117, 121

5. L. V. Miroshnik, A. V. Aleksandrov, and L. N. Tarasenko, Ukr. Khim. Zh., 1991, 57, 667.

6. U. S. Lal, M. C. Chattopadhyaya, and A. K. Dey, Indian J. Chem. Sect. A, 1980, 19, 390.
7. A. K. Jain, V. K. Gupta, and L. P. Singh, and U. Khurana, Analyst, 1997, 122, 583.

8. A. R. Fakhari, M. R. Ganjali, and M. Shamsipur, Anal. Chem., 1997, 69, 3693.

9. M. Javanbakht, M. R. Ganjali, and M. Shamsipur, Electroanalysis, 1999, 11, 81.

10. M. Shamsipur, S. Rouhani, H. Sharghi, M. R. Ganjali, and H. Eshgi, Anal. Chem., 1999, 71, 4839.

11. M. Shamsipur, S. Rouhani, M. R. Ganjali, H. Eshghi, and H. Sharghi, Microchem. J., 1999, 63, 202.

12. K. Niknam, Ph. D. Thesis, Shiraz University, 1997, Shiraz, Iran.

13. S. Kamata, A. Bhale, Y. Fukunaga, and H. Murata, Anal. Chem., 1988, 60, 2464.

14. M. Javanbakht, A. Shabani Kia, M. R. Darvich, M. R. Ganjali, and M. Shamsipur, Anal. Chim. Acta, 2000, 408, 75.

15. N. Alizadeh, S. Ershad, H. Naeimi, H. Sharghi, and M. Shamsipur, Fresenius J. Anal. Chem., 2000, 365, 511.

16. M. H. Mashhadizadeh and M. Shamsipur, Anal. Chim. Acta, 1999, 381, 111.

17. N. Tavakkoli and M. Shamsipur, Anal. Lett., 1996, 29, 269.

18. A. Rouhollahi, M. R. Ganjali, and M. Shamsipur, Talanta, 1998, 46, 1341.

19. N. Tavakkoli and M. Shamsipur, Anal. Chim. Acta, 1998, $31,2591$.

20. M. R. Gangali, A. Rouhollahi, A. R. Mardan, M. Hamzello, A. Moghimi, and M. Shamsipur, Microhem. J., 1998, 60, 122.

21. H. R. Pouretedal, H. Forghanian, and M. Shamsipur, Anal. Lett., 1998, 31, 2591.

22. M. R. Fathi, F. Darviche, and M. R. Ganjali, Anal. Lett., 2000, 33, 1025.

23. H. R. Pouretedal and M. Shamsipur, Fresenius J. Anal. Chem., 1998, 362, 415.

24. M. R. Ganjali, A. Moghimi, and M. Shamsipur, Anal. Chem., 1998, 70, 5259.

25. M. Shamsipur, M. Yousefi, and M. R. Ganjali, Anal. Chem., 2000, 72, 2391.

26. J. Koryta, Anal. Chim. Acta, 1990, 1, 233.

27. O. S. Wolfbeis, Anal. Chim. Acta, 1991, 181, 250.

28. T. Rosatzin, E. Bakker, K. Susuki, and W. Simon, Anal. Chim. Acta, 1993, 197, 280.

29. D. Amman, E. Pretsch, W. Simon, E. Lindler, A. Bezegh, and E. Pungor, Anal. Chim. Acta, 1991, 171, 1380. 
30. M. Huster, P. M. Gehring, W. E. Morf, W. Simon, E. 33. V. P. Godzepko and G. D. Christian, Anal. Chim. Acta, Lindler, J. Jeney, K. Toth, and E. Pungor, Anal. Chem., 1991, 63, 1380. 1984, 164, 279.

31. D. Amman, W. E. Morf, P. C. Meier, E. Pretsch, and W. Simon, Ion-Sel. Electrode Rev., 1983, 5, 3.

34. E. Bakker, Electroanalysis, 1997, 9, 7.

32. IUPAC Analytical Cheimistry Devision, Pure. Appl. Chem., 1976, 48, 127.

35. Y. Umezawa, K. Umezawa, and H. Sato, Pure Appl. Chem., 1995, 67, 507.

36. P. L. Bailey, "Analysis with Ion-Selective Electrodes", 1996, Heyden, London. 